\title{
ALPHA FETOPROTEIN; A PROGNOSTIC MARKER FOR EARLY DETECTION OF LIVER REGENERATION IN CASES OF ACUTE PARACETAMOL TOXICITY
}

\author{
Soha K. Ashry' ${ }^{\text {, Samar A. Ahmed }}{ }^{1}$, Hanan E. Salem ${ }^{1}$, M. M. Wahdan² \\ ${ }^{1}$ Department of Forensic Medicine and Clinical Toxicology, ${ }^{2}$ Department of Community, \\ Environmental and Occupational Medicine, Faculty of Medicine, Ain Shams University.
}

Corresponding Author: Soha K. Ashry

E-mail: soha_ashry@med.asu.edu.eg

Postal address: Department of Forensic Medicine and Clinical Toxicology, Faculty of Medicine, Ain Shams University, Abbasia square, Cairo, Egypt.

Telephone: +201114041404

\begin{abstract}
Background: Acute paracetamol toxicity is one of the commonest toxicities that lead to serious hepatic injury that could propagate to fulminant hepatic failure. An increase in serum level of alpha fetoprotein was observed following liver injury, and this increase was assumed to be associated with hepatic regeneration. Alpha fetoprotein (AFP) ratio (day 3/day 1 serum level) was proved to be a predictor for prognosis. Aim: The present study aims to evaluate the prognostic value of serum AFP and to evaluate the value of alpha fetoprotein ratio (day 2/day 1 serum level) for earlier prediction of the degree of liver regeneration after acute paracetamol toxicity. Methods: The present study was conducted on 32 patients with acute single paracetamol overdose admitted to the Poison Control Centre of Ain Shams University hospitals (PCC-ASUH). Liver routine laboratory tests were done on admission and on the second day in addition to measurement of the serum level of alpha fetoprotein. Results and Conclusions: Results showed that the increased serum level of alpha fetoprotein was linked to regeneration of the liver which was suggested by shortening of the duration of hospital stay. In addition, the AFP ratio day2/day1 serum level was suggested by the study results to be an efficient prognostic factor in cases with acute paracetamol toxicity for early prediction of the state of regeneration of the liver.
\end{abstract}

Key words: Acute paracetamol toxicity, Alpha fetoprotein, Liver regeneration

\section{INTRODUCTION}

Paracetamol is an analgesic, antipyretic used to treat mild to moderate pain. It is a widely available over the counter (OTC) drug presented in numerous formulations either as a single agent or in combination with other agents. Despite being a remarkably safe drug, toxicity with paracetamol is one of the commonest toxicities seen in the emergency rooms. This is attributed to its wide availability and its affordable price (Hendricson, 2011).

Paracetamol toxicity is one of the commonest causes of morbidity. With the liver being its target organ, paracetamol toxicity causes serious hepatic injury which could propagate to fulminant hepatic failure. Its metabolite namely $\mathrm{N}$-Acetyl-p-benzoquinoneimine (NAPQI) causes drastic damage to hepatocytes through oxidative stress and glutathione depletion (Jaeschke, 2015; Yoon et al., 2016). 
Liver routine tests include serum transaminases namely alanine aminotransferase ALT and aspartate aminotransferase AST increase within 24 hours from ingestion and peak at 72 hours making it hard to detect the degree of liver affection in the early hours after toxicity. These tests also include serum bilirubin, alkaline phosphatase as well as prothrombin time PT, international normalization ratio INR and serum albumin which collectively reflect the degree of impairment of liver function (Yoon et al., 2016).

Alpha Fetoprotein (AFP) a glycoprotein produced by embryonic yolk sac and fetal liver is produced in high levels and its serum concentration declines throughout pregnancy and after birth (Mizejewski, 2003). In adults, AFP high concentrations are seen in patients with some hepatic malignancies as well as other organs' malignancies and considered a tumor marker for these cases (Huang \& Ren, 2011; Azab et al., 2016).

In previous studies, an increase in the serum level of AFP was observed following liver injury, and this increase was associated with hepatic regeneration and a favorable outcome (Schmidt \& Dalhoff, 2005 \& Michalopoulos, 2011). This could be attributed to the fact that immature hepatoblasts have features that resemble those of fetal hepatocytes (Yang et al., 2002). Another study used the measured ratio of AFP in day 3 to day 1 serum level as a predictor for prognosis (Schiødt et al., 2006).

The present study aims to evaluate the prognostic value of serum AFP and to evaluate the value of AFP ratio day 2: day 1 serum level for earlier prediction of liver regeneration after acute paracetamol toxicity.

\section{PATIENTS \& METHODS}

Patients and controls

This prospective case control study was conducted on 32 patients with acute single paracetamol overdose admitted to the Poison Control Centre of Ain Shams University hospitals (PCC-ASUH) in the period from June 2016 till December 2016. They were compared to 20 healthy controls (as proved by examination and lab investigations) matched for age and sex.

\section{Inclusion and exclusion criteria}

The inclusion criteria for the study were history of recent acute single paracetamol overdose and a delay between 4-24 hours (so that the Rumack Matthew nomogram rules could be applied). The exclusion criteria were positive history of liver disease or tumors, alcohol intake, coingestion of other hepatotoxic agents, treatment with anticoagulants and pretreatment before arrival to the PCC.

\section{Ethical issues}

A valid informed consent was obtained from each patient as well as from each control subject or his guardian (for patients aged less than 18 years) as well as an approval of Faculty of Medicine Ain-Shams University Research Ethics Committee (FMASU REC). In order to secure confidentiality, specimens were coded and anonymously stored.

\section{Groups}

Paracetamol plasma level was measured for patients and according to Rumack Matthew nomogram (Olson, 2012) they were divided into 3 groups:

- Mild toxicity: Paracetamol level less than $140 \mu \mathrm{g} / \mathrm{ml}$ (no hepatic toxicity)

- Moderate toxicity: Paracetamol level ranging from 140-200 $\mu \mathrm{g} / \mathrm{ml}$ (possible hepatic toxicity) 
- Severe toxicity: Paracetamol level above $200 \mu \mathrm{g} / \mathrm{ml}$ (probable hepatic toxicity) or less than $200 \mu \mathrm{g} / \mathrm{ml}$ but with AST level above 1000IU/L denoting severe liver toxicity (Salhanick \& Shannon, 2007).

\subsection{Data collection}

Data was collected from each patient and control and they fell in 3 categories: demographic data (age, sex), intoxication data (dose, form, route, manner of overdose, coingestions and time from ingestion to first blood sample), clinical data (symptoms of vomiting and abdominal pain, vital signs and signs of jaundice, hepatomegaly and ascites in addition to level of consciousness). The clinical data were assessed on admission and during hospital stay, and patients were followed up till discharge where the length of hospital stay was estimated as well as the outcome.

\section{Investigations}

Investigations were done using serum samples. Venous blood samples were collected from each patient and control participants under aseptic precautions by a plastic disposable syringe. For each sample the following parameters were tested: paracetamol level, serum aspartate aminotransferase (AST), serum alanine aminotransferase kit (ALT), serum alkaline phosphatase (ALP), international normalization ratio (INR), partial thromboplastin time (PTT), serum bilirubin, serum albumin and alpha fetoprotein serum level. These tests were done twice for each patient on admission on day 1 and repeated on day 2. For controls, tests were done only once.

Paracetamol level was measured at wave length $450 \mathrm{~nm}$ using SPEKOL 11 analyzer. AST and ALT were assayed by quantitative kinetic assay method where AST level was assayed using aspartate aminotransferase kit (291002, spectrum, Obour city, Cairo, Egypt), and ALT level was assayed using alanine aminotransferase kit (292002, spectrum, Obour city, Cairo, Egypt). ALP activity was quantified colorimetrically at wave length $405 \mathrm{~nm}$. INR was calculated from the ratio of the patient's prothrombin time to a normal (control) sample. Serum total bilirubin was measured quantitatively where bilirubin concentration is determined by measuring the increase in absorbance at $578 \mathrm{~nm}$.

Alpha fetoprotein serum level determination: blood samples were obtained and sera were spun within 2 hours and stored at $-80^{\circ} \mathrm{C}$. Alpha fetoprotein level was measured using alpha fetoprotein enzyme immunoassay kit (ELIZA) ICN pharmaceutical USA Catalogue Number 07B07102 following the manufacturer's instructions. The AFP ratio was defined as the serum AFP concentration on day 2 divided by that observed on day 1 for the same patient.

\section{Statistical analysis}

Statistical analysis was performed with IBM $®$ SPSS ${ }^{\circledR}$ Statistics Version 20 for Windows. Quantitative data were presented as mean \pm standard deviation $( \pm$ SD), median and range values. Wilcoxon signed rank test $\mathrm{t}$ - test was done for comparing quantitative variables between before and after intervention. Mann Whitney test was done for comparing quantitative variables between 2 independent groups as case and control. ANOVA test was done for comparing quantitative variables between more than 2 independent groups as mild, moderate and severe. Qualitative data were expressed as frequencies (n) and percentage $(\%)$. Correlation test was used to correlate between quantitative 
variables as alpha fetoprotein, and length of hospital stay. Regression analysis was done for detection of variables affecting length of hospital stay. $\mathrm{P}$-value $\leq 0.05$ was considered significant.

\section{RESULTS}

Comparison between controls and patients' data on admission:

Among the 52 study participants, there were 32 patients and 20 controls. Males comprised $40 \%$ of the studied patients while females comprised $60 \%$. Their age ranged from 16 to 43 years. There was no statistical significant difference between the two groups regarding sex or age. As regards laboratory results, on admission and before treatment, the serum levels of AST, bilirubin and alpha fetoprotein were significantly higher in patients than in controls.

\section{Clinico-pathological} characteristics of the patients

Among all the studied patients (32), there was no history of alcohol consumption, liver diseases, hepatomegaly and ascites or pretreatment before hospital intervention. All patients recorded taking oral paracetamol in tablet form with variable doses. They all recorded taking the drug in a suicidal attempt.

Regarding the clinical findings, $85 \%$ of the patients were complaining of vomiting which was not accompanied by abdominal pain, jaundice or coma.

Regarding the 3 groups of the present study, the mild toxicity group comprised 13 patients (40.6\%), the moderate toxicity comprised 10 patients $(31.2 \%)$ and the severe toxicity group comprised 9 patients (28.2\%).

\section{Comparison between different levels of severity among patients}

There was a significant difference between the three levels of severity as regards alpha fetoprotein serum level on day 1 (on admission), alpha fetoprotein ratio, and the length of hospital stay $(\mathrm{P}$ value $<0.05)$. These findings are illustrated in table 1 .

\section{Comparison between the} laboratory findings in day 1 (on admission) and day 2 among patients

Laboratory results in day 1 (on admission) and day 2 revealed a significant decrease in paracetamol level and a significant increase in the levels of AST, ALT, ALP, and alphafetoprotein in patients on day 2 when compared to the laboratory results on day 1 . These findings are illustrated in table 2.

Correlation between different factors and length of hospital stay

Correlation between the duration of hospital stay and the patients' clinical data are shown in tables $3,4 \& 5$. There was a highly significant positive correlation $(\mathrm{p}<0.001)$ between the duration of hospital stay and the measured serum level of paracetamol ( $\mathrm{r}$ $=.357$ ). There was also a correlation between the duration of hospital stay and the increase in the serum level of $\operatorname{AST}(r=.501)$, PTT $(r=.519)$, bilirubin $(\mathrm{r}=.553)$, measured on day 1 . In addition, there was a negative correlation between the duration of hospital stay and the serum levels of ALP $(r=-.641)$, albumin $(r=-.739)$, and alpha fetoprotein ratio $(\mathrm{r}=-.688)$ measured on day 1 . However, there was no correlation between the duration of hospital stay and hours of delay as well as laboratory data measured on day 1 namely paracetamol level, ALT, INR, in addition to alpha fetoprotein level measured on day 2. 
Evaluation of alpha fetoprotein ratio (day 2 serum level/day 1 serum level) as a prognostic factor

The multivariate analysis represented in table 6 and fig. 1 revealed that alpha fetoprotein ratio (HR -64.190, $\mathrm{P}=0.000)$ was an independent prognostic factor for the length of hospital stay. The coefficient indicates that for each increasing fold of the ratio of serum level of alpha fetoprotein (increase by 1 whole number in the ratio result), one can expect the duration of hospital stay to decrease by an average of 64.19 hours. In contrary, the dose of ingested paracetamol (HR 3.137, $\mathrm{P}=0.183$ ) was not a prognostic factor for the length of hospital

stay.

Table (1): Comparison between different levels of severity:

\begin{tabular}{|c|c|c|c|}
\hline & & Mean \pm SD (95\% C.I.) & $\mathbf{P}^{\text {II }}$ \\
\hline \multirow[t]{3}{*}{ Age } & Mild & $19.69 \pm 4.131(17.20-22.19)$ & \multirow[t]{3}{*}{$.000 *$} \\
\hline & Moderate & $31.10 \pm 6.99(26.09-36.11)$ & \\
\hline & Severe & $23.67 \pm 5.41(19.51-27.82)$ & \\
\hline \multirow[t]{3}{*}{ Dose } & Mild & $13.46 \pm 3.05(11.62-15.30)$ & \multirow[t]{3}{*}{.114} \\
\hline & moderate & $14.00 \pm 4.83(10.54-17.46)$ & \\
\hline & Severe & $17.89 \pm 7.01(12.50-23.28)$ & \\
\hline \multirow{3}{*}{$\begin{array}{c}\text { Alpha } \\
\text { fetoprotein } \\
\text { ratio }\end{array}$} & Mild & $3.38 .85(2.86-3.89)$ & \multirow[t]{3}{*}{$.000 *$} \\
\hline & Moderate & $2.16 \pm .46(1.83-2.49)$ & \\
\hline & Severe & $2.06 \pm .25(1.87-2.26)$ & \\
\hline \multirow{3}{*}{$\begin{array}{c}\text { Duration of } \\
\text { stay }\end{array}$} & Mild & $44.31 \pm 59.48(8.37-80.25)$ & \multirow[t]{3}{*}{$.000 *$} \\
\hline & Moderate & $105.60 \pm 23.19(89.01-122.19)$ & \\
\hline & Severe & $226.67 \pm 40.00(195.92-257.41)$ & \\
\hline \multirow{3}{*}{$\begin{array}{c}\text { alpha } \\
\text { fetoprotein } 1\end{array}$} & Mild & $2.15 \pm .80(1.67-2.63)$ & \multirow[t]{3}{*}{$.000^{*}$} \\
\hline & Moderate & $3.50 \pm .71(2.99-4.01)$ & \\
\hline & Severe & $3.89 \pm .33(3.63-4.15)$ & \\
\hline \multirow{3}{*}{$\begin{array}{c}\text { alpha } \\
\text { fetoprotein } 2\end{array}$} & Mild & $6.85 \pm 1.91(5.69-7.99)$ & \multirow[t]{3}{*}{.352} \\
\hline & Moderate & $7.60 \pm 2.37(5.91-9.29)$ & \\
\hline & Severe & $8.00+1.00(7.23-8.77)$ & \\
\hline
\end{tabular}

(II) ANOVA test was used. 
Table (2): Comparison between day 1 and day 2 among cases

\begin{tabular}{|c|c|c|}
\hline & $\begin{array}{c}\text { Median (Minimum } \\
\text { Maximum) }\end{array}$ & $\begin{array}{c}\text { Wilcoxon signed rank } \\
\text { test }\end{array}$ \\
\cline { 1 - 2 } paracetamol day 1 & $99.5(21.0-185.0)$ & $.000^{*}$ \\
\hline paracetamol day 2 & $11.5(1.0-45.0)$ & \multirow{2}{*}{$.000^{*}$} \\
\hline AST 1 & $35.0(19.0-53.0)$ & \multirow{2}{*}{$.000^{*}$} \\
\hline AST 2 & $503.0(32.0-6124.0)$ & \multirow{2}{*}{$.000^{*}$} \\
\hline ALT 1 & $34.0(12.0-56.0)$ & \multirow{2}{*}{.705} \\
\hline ALT 2 & $139.5(35.0-6908.0)$ & \multirow{2}{*}{.106} \\
\hline ALP 1 & $21.0(4.0-45.0)$ & \\
\hline ALP 2 & $55.0(7.0-301.0)$ & .317 \\
\hline INR 1 & $1.0(1.0-2.0)$ & \\
\hline INR & $1.0(1.0-3.0)$ & .317 \\
\hline PTT 1 & $29.5(25.0-41.0)$ & \\
\hline PTT 2 & $31.0(27.0-37.0)$ & $.000^{*}$ \\
\hline Bilirubin 1 & $1.0(.0-3.0)$ & \\
\hline Bilirubin 2 & $1.0(.0-3.0)$ & \\
\hline Albumin 1 & $3.0(3.0-4.0)$ & \\
\hline Albumin 2 & $3.0(3.0-4.0)$ & \\
\hline Alpha-fetoprotein 1 & $3.0(1.0-4.0)$ & \\
\hline Alpha-fetoprotein 2 & $7.0(4.0-11.0)$ & \\
\cline { 1 - 2 } & & \\
\hline & & \\
\hline
\end{tabular}

Table (3): Correlation between different factors and length of hospital stay:

\begin{tabular}{|c|c|c|c|c|c|}
\hline & $\begin{array}{c}\text { Duration of } \\
\text { stay (hrs) }\end{array}$ & Age & $\begin{array}{c}\text { Dose } \\
(\mathbf{G})\end{array}$ & $\begin{array}{c}\text { Delay } \\
\text { (hs) }\end{array}$ & $\begin{array}{c}\text { Paracetamol } \\
\text { day 1 (ug/ml) }\end{array}$ \\
\hline Duration of stay (hrs) & 1 & & & & \\
\hline Age & .001 & 1 & & & \\
\hline dose (G) & $.357^{*}$ & -.273 & 1 & & \\
\hline delay (hs) & .218 & -.017 & -.330 & 1 & \\
\hline Paracetamol day 1 (ug/ml) & -.032 & $-.556^{* *}$ & $.742^{* *}$ & $-.479^{* *}$ & 1 \\
\hline
\end{tabular}

Table (4): Correlation between different laboratory findings and length of hospital stay:

\begin{tabular}{|c|c|c|c|c|c|c|c|c|}
\hline & $\begin{array}{c}\text { Duration } \\
\text { of stay }\end{array}$ & AST 1 & $\begin{array}{c}\text { ALT } \\
\mathbf{1}\end{array}$ & ALP 1 & $\begin{array}{c}\text { INR } \\
\mathbf{1}\end{array}$ & PTT 1 & $\begin{array}{c}\text { Biliru } \\
\text { bin 1 }\end{array}$ & $\begin{array}{c}\text { Album } \\
\text { in 1 }\end{array}$ \\
\hline $\begin{array}{c}\text { Duration of } \\
\text { stay (hrs) }\end{array}$ & 1 & & & & & & & \\
\hline AST 1 & $.501^{* *}$ & 1 & & & & & & \\
\hline ALT 1 & .241 & $.381^{* *}$ & 1 & & & & & \\
\hline ALP 1 & $-.641^{* *}$ & $-.312^{*}$ & .009 & 1 & & & & \\
\hline INR 1 & .211 & .070 & .019 & -.167 & 1 & & & \\
\hline PTT 1 & $.519^{* *}$ & $.396^{* *}$ & .212 & -.204 & $.473^{* *}$ & 1 & & \\
\hline Bilirubin 1 & $.553^{* *}$ & $.377^{* *}$ & .169 & $-.443^{* *}$ & -.026 & .137 & 1 & \\
\hline Albumin 1 & $-.739^{* *}$ & $-.438^{* *}$ & $-.312^{*}$ & $.609^{* *}$ & -.255 & $-.409^{* *}$ & $-.332^{*}$ & 1 \\
\hline
\end{tabular}

$\left(^{*}\right)$ statistically significant $\&\left(^{* *}\right)$ highly statistically significant 
Table (5): Correlation between alpha fetoprotein levels and ratio and length of hospital stay:

\begin{tabular}{|c|c|c|c|c|}
\hline & $\begin{array}{c}\text { Duration of } \\
\text { stay }\end{array}$ & $\begin{array}{c}\text { Alpha } \\
\text { fetoprotein ratio }\end{array}$ & $\begin{array}{c}\text { Alpha } \\
\text { fetoprotein 1 }\end{array}$ & $\begin{array}{c}\text { Alpha } \\
\text { fetoprotein 2 }\end{array}$ \\
\hline $\begin{array}{c}\text { Duration of stay } \\
\text { (hrs) }\end{array}$ & 1 & & & \\
\hline $\begin{array}{c}\text { Alpha } \\
\text { fetoprotein ratio }\end{array}$ & $-.688^{* *}$ & 1 & 1 & \\
\hline $\begin{array}{c}\text { Alpha } \\
\text { fetoprotein 1 }\end{array}$ & $.815^{* *}$ & $-.749^{* *}$ & $.514^{* *}$ & 1 \\
\hline $\begin{array}{c}\text { Alpha } \\
\text { fetoprotein 2 }\end{array}$ & .271 & .010 & & \\
\hline
\end{tabular}

Table (6): Multivariate analysis results showing the relation between alpha fetoprotein day2/day1 ratio and duration of hospital stay

\begin{tabular}{|c|c|c|c|c|c|c|c|}
\hline & \multicolumn{2}{|c|}{$\begin{array}{c}\text { Unstandardized } \\
\text { Coefficients }\end{array}$} & $\begin{array}{c}\text { Standardized } \\
\text { Coefficients }\end{array}$ & \multirow{2}{*}{$\mathbf{T}$} & \multirow{2}{*}{} & \multicolumn{2}{|c|}{$\begin{array}{c}\text { 55.0\% Confidence } \\
\text { Interval for B }\end{array}$} \\
\cline { 2 - 4 } \cline { 6 - 8 } & $\mathbf{B}$ & $\begin{array}{c}\text { Std. } \\
\text { Error }\end{array}$ & Beta & & & $\begin{array}{c}\text { Lower } \\
\text { Bound }\end{array}$ & $\begin{array}{c}\text { Upper } \\
\text { Bound }\end{array}$ \\
\hline (Constant) & $\begin{array}{c}236.75 \\
8\end{array}$ & 57.007 & & 4.153 & .000 & 120.166 & 353.350 \\
\hline $\begin{array}{c}\text { Alpha fetoprotein } \\
\text { ratio }\end{array}$ & -64.190 & 13.665 & -.638 & -4.697 & $.000^{*}$ & -92.139 & -36.241 \\
\hline
\end{tabular}

Figure (1): Relation between alpha fetoprotein day2/day1 ratio and duration of hospital stay

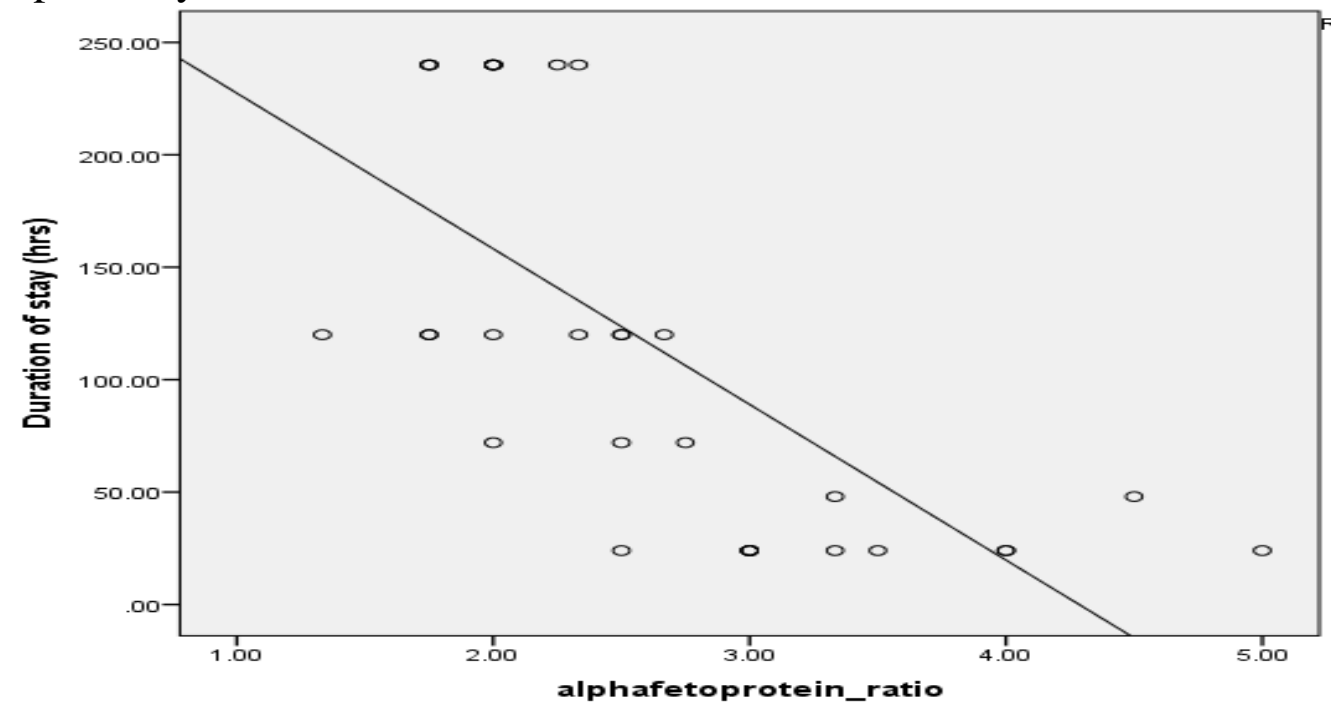

\section{DISCUSSION:}

It is important to predict the degree of liver affection or regeneration in patients with paracetamol toxicity in order to be prepared for the proper management. Additionally, estimation of the duration of hospital stay which is influenced by financial issues of the patient is important to guard against posing a burden on the health institution itself (Shakil et al., 2004). 
In the present study all of the patients were of the young age group (16-41 years) with mean age $22 \pm 6$. They all reported taking the drug with suicidal intentions. The prevalence of this age group in the present study could be attributed to the increased social stresses, economic instability, unemployment and the availability of the drug as an OTC (Wasserman \& Cheng, 2005). All patients in the study were discharged after a favorable outcome of complete recovery. This was explained by Schmidt (2005) and Yoon et al. (2016) who reported that younger individuals can tolerate extensive liver injury. They also stated that young people aged less than 40 years have a larger functioning liver cell mass with an efficient ability of conjugation and abundant glutathione stores; together with a better ability to compensate acute hepatic dysfunction via higher extra hepatic metabolism of toxic substances (e.g ammonia could be metabolized by striated muscle tissue).

The serum levels of AST, bilirubin, AFP were significantly higher in patients than in controls in the present study. AST serum level is known to increase in paracetamol-induced liver injury in the first 24 hours postingestion but high levels may be seen as early as 12 hours in heavy intoxication (Berger et al., 2015). Bilirubin serum levels also increase in cases of hepatotoxicity in the first 24 hours and denotes actual liver affection (Remien et al., 2012). AFP serum level was reported by previous studies to increase in cases of liver affection and its continuous increase was linked to good prognosis in these cases (Schmidt \& Dalhoff, 2005; Schiødt et al., 2006).

In the present study, there was a significant difference between the three study groups as regards the duration of hospital stay. This coincides with the findings by Zain et al. (2006) who proved the fact that the higher the paracetamol dose $(>140 \mathrm{mg} / \mathrm{kg})$ ingested, the longer the duration of hospital stay. This was confirmed in our case by elevated serum paracetamol levels and increased ALT, AST, ALP, PTT and bilirubin serum levels in the severely intoxicated group. These laboratory findings reflect liver cells breakdown, as well as impaired synthetic and conjugation functions of hepatocytes (Berger et al., 2015).

A highly significant negative correlation was found between the alpha fetoprotein level measured in day 1 and the duration of hospital stay. This finding agrees with a study conducted by Schmidt and Dallhof (2005) who concluded that an increase in alpha fetoprotein was strongly associated with good prognosis in patients with acute paracetamol toxicity.

A highly significant correlation was found between the alpha fetoprotein serum level day 2 to day 1 ratio and shortening of the duration of hospital stay. This suggested a favorable outcome in patients with paracetamol induced liver injury and short hospital stay duration when higher values of the ratio are seen. A study by Schiødt et al. (2006) recorded a similar finding but used a ratio of AFP serum level day3/day1. They proved that higher day 3 to day 1 ratio of alpha fetoprotein carries a better prognosis of survival. They recommended the use of alpha fetoprotein ratio rather than using serial alpha fetoprotein measurements, as the ratio reflects clearly the status of liver regeneration; whereas the mere increase in alpha fetoprotein levels are more related to the characteristic pattern of liver cell injury rather than to the severity of liver affection. They also 
recommended the trial of using the alpha fetoprotein level ratio of day2/day1which was used in the present study and proved efficient in predicting the outcome of liver affection.

Despite the increased efficiency of the alpha fetoprotein ratio over alpha fetoprotein level measurement in predicting the outcome of liver affection, yet this does not negate the fact that measurement of alpha fetoprotein level is a good prognostic tool being financially sound, of low cost and readily available. In addition, diagnosis could be missed in cases of co-ingestion; so having AFP level measured could help draw the attention to liver state in many cases of overdose.

\section{CONCLUSIONS \& RECOMMENDATIONS:}

The present study concluded that serum level of alpha fetoprotein is a useful prognostic indicator in cases of acute paracetamol toxicity. The AFP serum level ratio day2/day1 is an efficient prognostic factor in these cases for early prediction of the state of regeneration in the liver. Further studies are recommended to test the effects of antidote administration on the serum level of AFP.

\section{ACKNOWLEDGEMENTS}

This research did not receive any specific grant from funding agencies in the public, commercial, or not- forprofit sectors; it was totally funded by the authors. The authors declare that there is no conflict of interest.

\section{REFERENCES}

Azab SMS, Hirshon JM, Hayes BD, El-Setouhy M, Smith GS, Sakr ML et al. (2016): Epidemiology of acute poisoning in children presenting to the poisoning treatment center at Ain Shams University in Cairo, Egypt, 20092013. Clin Toxicol. 54(1):20-6.

Berger RD, Bhattacharyya S, Yang X, Gill PS, Schnackenberg LK, James LP. (2015): Translational biomarkers of acetaminopheninduced acute liver injury. Archives of Toxicology 1-26.

Hendricson R.G. (2011): Acetaminophen. In: Goldfrank's Toxicologic Emergencies, $9^{\text {th }}$ edition, Goldfrank LR, Hoffman S, Nelson S, Howland MA, Lewin A, Flomenbaum N. (eds), McGrawHill, USA. p. 483-499.

Huang X \& Ren J. (2011): Gold nanoparticles based chemiluminescent resonance energy transfer for immunoassay of alpha fetoprotein cancer marker. Analytica Chemica Acta. 686:115120.

Jaeschke, H. (2015): Acetaminophen: Dose-dependent drug hepatotoxicity and acute liver failure in patients. Dig Dis. 33:464471.

Michalopoulos GK. (2011): Liver regeneration: alternative epithelial pathways. The international journal of biochemistry \& cell biology. 43(2):173-179.

Mizejewski GJ. (2003): Levels of alpha-fetoprotein during pregnancy and early infancy in normal and disease states. Obstet Gynecol Surv. 58:804-826.

Olson KR. (2012): Acetaminophen. In: Olson's Poisoning \& Drug Overdose, $6^{\text {th }}$ edition, Olson KR (ed.), McGraw-Hill, USA. p. 69-72.

Remien CH, Adler FR, Waddoups L, Box TD, Sussman NL. (2012): Mathematical modeling of liver injury and dysfunction after 
acetaminophen overdose: early discrimination between survival and death, Hepatology. 56(2):727734.

Salhanick SD \& Shannon MW. (2007): Acetaminophen. In: Haddad and Winchester's clinical management of poisoning and drug overdose, $4^{\text {th }}$ edition, Haddad LM, Winchester JF. (eds.), Saunders, Elsevier Inc. p. 825-834.

Schiødt FV, Ostapowicz G, Murray N, Satyanarana R, Zaman A, Munoz S, M.Lee W. (2006): Alpha-fetoprotein and prognosis in acute liver failure. Liver Transplantation. 12(12):17761781.

Schmidt LE, \& Dalhoff K. (2005): Alpha-fetoprotein is a predictor of outcome in acetaminophen-induced liver injury. Hepatology. 41(1):2631.

Schmidt LE. (2005): Age and paracetamol self-poisoning. Gut. 54(5):686-90.

Shakil AO, Kramer D, Mazariegos GV, Fung JJ, Rakela J. (2004):
Acute liver failure: clinical features, outcome analysis, and applicability of prognostic criteria. Liver Transpl 6:163-169.

Wasserman D \& Cheng Q, X. (2005):

Global suicide rates among young people aged 15-19. World Psychiatry. 4(2):114-120.

Yang SS, Cheng KS, Lai YC, et al. (2002): Decreasing serum alphafetoprotein levels in predicting poor prognosis of acute hepatic failure in patients with chronic hepatitis B. J Gastroenterol 37:626-632.

Yoon E, Babar A, Choudhary M, Kutner M, Pyrsopoulos N. (2016): Acetaminophen-Induced Hepatotoxicity: a Comprehensive Update. Journal of Clinical and Translational 4(2):131-142.

Hepatology.

Zain MZ, Fathelrahman AI, Ab Rahman

AF.

(2006):

Characteristics and outcomes of paracetamol poisoning cases at a general hospital in Northern Malaysia. Singapore Medical Journal. 47(2):134-7. 
ألفا فيتوبروتين؛ كمؤشر للتبوُ المبكر بحدوث تجدد فى خلايا الكبد فى مرحلة الشفاء بعد

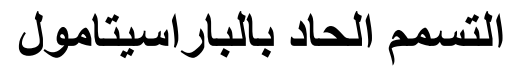

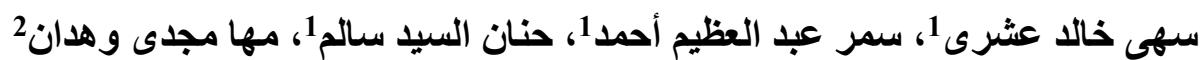

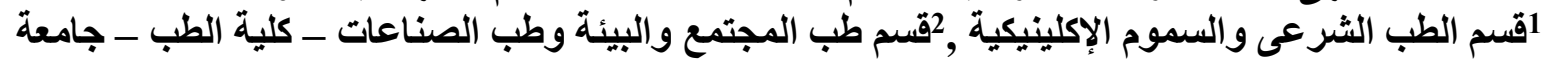
عين شمس

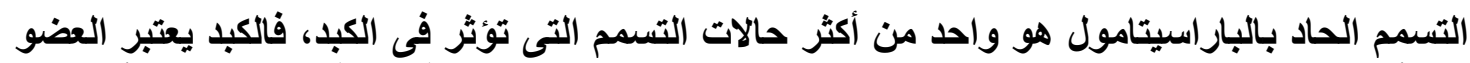

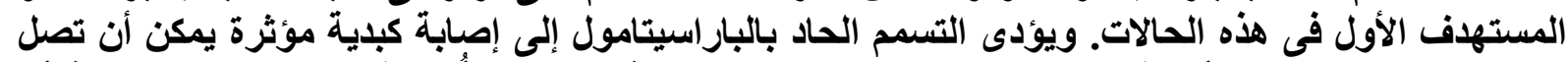

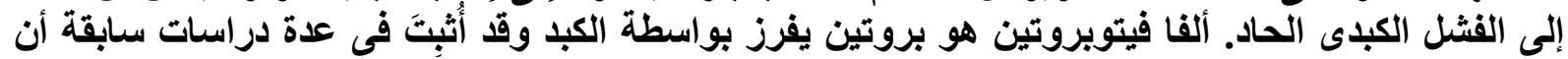

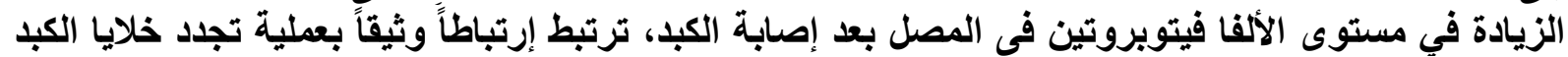

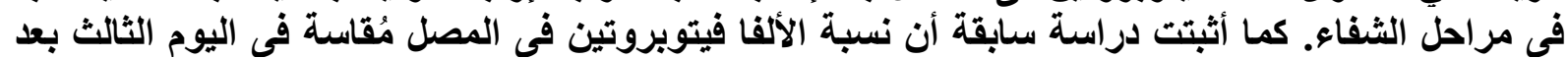

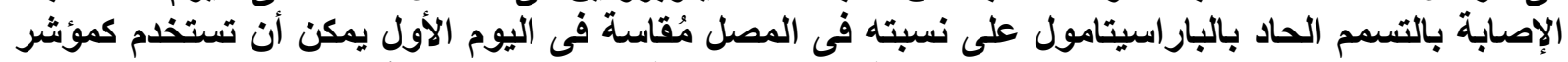

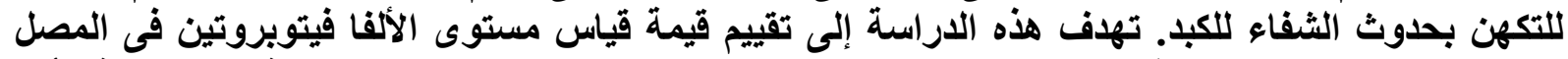

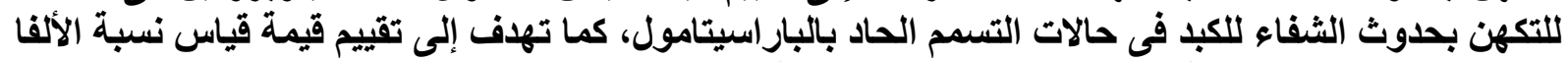

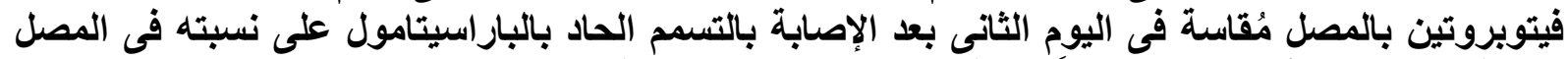

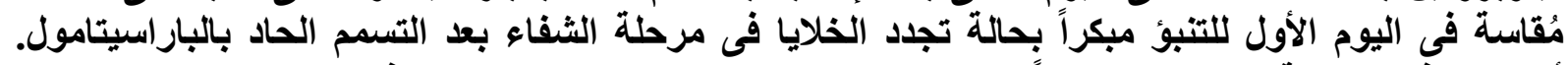

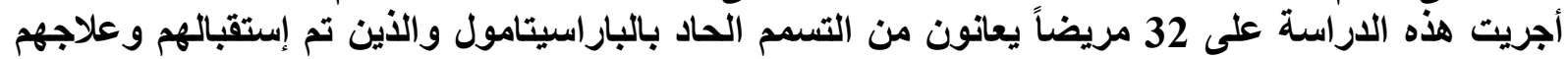

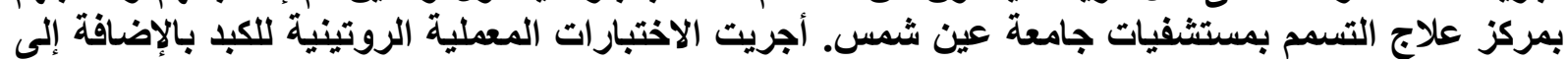

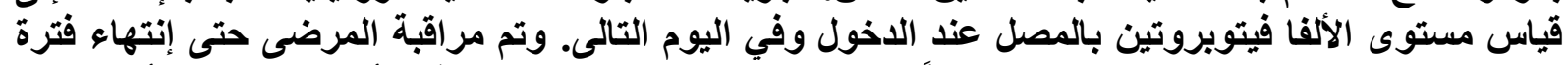

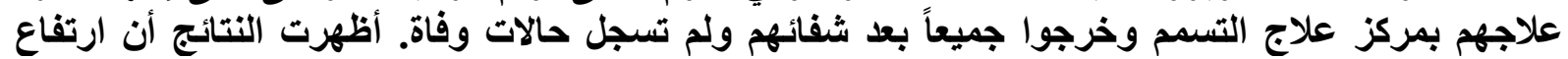

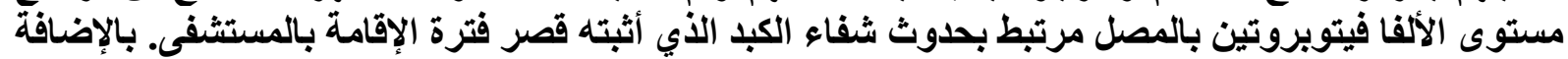

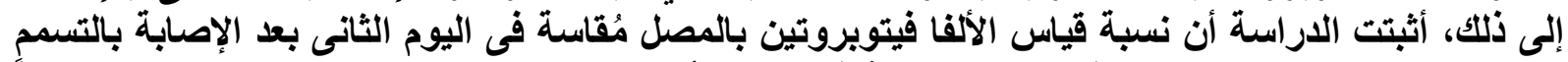

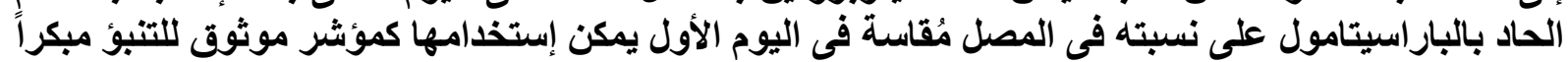

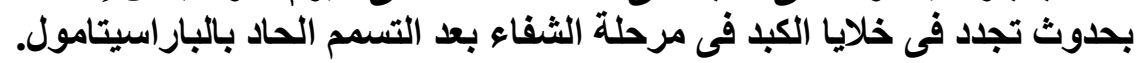

